psychotherapists (1:10,000 population) in office practice has also contributed to the situation that out-patient care of mentally ill patients within the community is satisfactory. Nevertheless, a number of old chronic mentally ill patients are still in psychiatric hospitals because up to now there were no adequate services within the community for them.

In East Germany the reform of psychiatry essentially started only after reunification. Therefore the large state mental hospitals are still very prevalent there. An out-patient psychiatric infrastructure comparable to that in West Germany will slowly develop over the next few years. The psychiatric departments in general hospitals will be the engine of this development. There already are promising attempts, mostly in medium-sized cities. Because financial resources are more scarce and the political priorities of 1994 are different from 1974, this process in the East will probably take longer than in West Germany. This means that in almost every area of society, the gap between West and East Germany will continue for many more years.

M. Bauer, Professor, Städtlsche Kltniken Offenbach, Psychiatrische Klinik, Starkenburgring 66, 63069 Offenbach, Germany

\title{
East and west, old and new: the College tour of Germany
}

\author{
S.D. Martin, B. Bende, B. Breitner, M. Laker and F. Leslie
}

German psychiatry is emerging from a black past to a challenging future. Under the Nazis it is thought that about 100,000 psychiatric patients were killed and 300,000 were compulsorily sterilised. Services for the mentally ill had also been adversely affected by two world wars and recession. For 50 years there was little progress. By the 1970 s, the government and other institutions took more interest in mental health. Community facilities began to appear such as day centres. Long-stay patients are now being discharged from hospitals and asylums have closed in some states.

On 26 September 1993, a party of 26 psychlatrists went on a week-long Study Tour to Northern Germany visiting Lübeck, Kiel, Rostock and Hamburg. It was admirably organised by Dr Cyril Davies from the British side and Dr Alexander Boroffka from the German Association for Psychiatry and Neurology.

\section{Health insurance}

It is mandatory for anybody in training or employment in Germany to have health insurance. Unemployed people or those receiving social benefits are also included.
Health insurance organisations pay doctors in their own practice every three months for their patient contacts and interventions with itemised fees. Insurance organisations, together with local government, negotiate contracts with individual hospitals for in-patient treatment. Recent research has shown $20 \%$ of the population have had insurance payments for some kind of mental health treatment.

Rehabilitation services, including addictions, are often funded by health insurance organisations and pension funds who, as purchasers, can restrict funding and prevent treatment.

\section{Private practice}

Hospital psychiatrists see almost exclusively inpatients. Most out-patient treatment is provided by specialists in their own practices in the community. Usually called 'private practice' the term is misleading as health insurance organisations pay for treatment. The system allows patients to choose psychiatrists but they must usually arrange their own follow-up after discharge from hospital.

There is very little multidisciplinary team work. Psychiatrists in their own practice are 


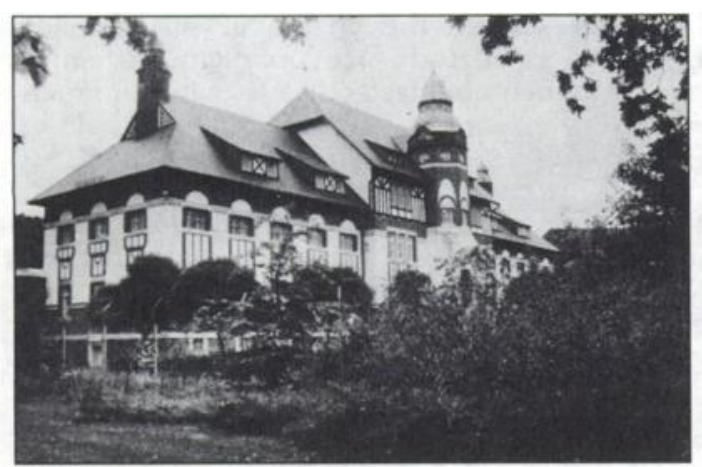

Forensic Unit, Neustadt Hospltal.

independent but isolated from colleagues. They are not bound to sectors and are in competition with each other. Practice populations vary from 5,000 to 15,000 . Each of the 151 private psychiatrists in the northern state of Schleswig-Holstein does an average of 500 consultations every three months. Most also do neurological practice and six even have CT scanners in their clinics.

\section{Training}

Germany has over 30 university departments of psychiatry. The tour visited that of Professor Horst Dilling at Lübeck.

All German medical students have to sit an MCQ examination, including psychiatry. The extent of practical and theoretical teaching varies between universities. Students attend seminars and take patients' histories but are not attached to a psychiatric firm as in Britain.

Specialist training is unstructured and consists almost exclusively of service commitments. After a minimum of three years experience in psychiatry and one year in neurology a trainee can apply to become a specialist in psychiatry. Until recently most psychiatrists did between five and nine years postgraduate training.

A new psychotherapeutic subspeciality is being created in psychosomatic medicine with separate in-patient units and training. German psychosomatic medicine deals with such problems as neuroses, eating disorders, ulcerative colitis, asthma and post cardiac surgery cases.

\section{Acute services}

A report made to the central West German government in 1975 recommended developing psychiatric services based on the British model. After World War II the population of SchleswigHolstein doubled without an increase in psychiatric beds. Then in 1990 Schleswig-Holstein was given 100 million DM (about $540 \mathrm{~m}$ ) for mental

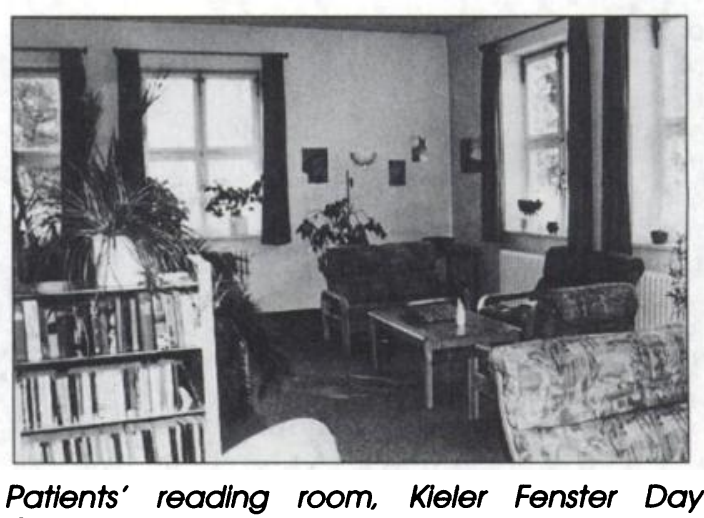

Centre.

health out of 500 million DM for the whole country, a disproportionately large sum because of a carefully prepared case. It is intended that this will be used to develop community services. Four new day hospitals have already been opened in the state and a further seven are definitely planned.

Schleswig-Holstein retains three large rural psychiatric hospitals. We visited Neustadt Hospital which has 960 beds, 255 of which are acute, 40 are neurological, 480 long stay and 185 forensic. The hospital was celebrating the centenary of its opening in the week of our visit. There are 3,000 admissions per year, over $50 \%$ of which are addiction problems. On the acute wards men and women have separate sleeping corridors with four bed units. There were no curtains around the beds and each one had an oxygen point.

German public opinion is strongly against anything that appears to be experimenting on psychiatric patients because of the Nazi past. As a result ECT is not given in some units and is little used in others. At Neustadt Hospital about four patients a year have it for depressive stupor or catatonia. The university hospital at Lübeck uses it a little more often.

\section{Former East Germany}

On the tour we saw Rostock Hospital, built between 1893 and 1896 for 200 psychiatric patients. After German unification on 3 October 1990 the hospital beds were reduced to 80 , not many for a catchment population of 360,000 . Lack of money was clear. Almost all the buildings were in great need of redecoration and the cement rendering was peeling off the outsides. Professor Klaus Ernst, the Medical Director, lamented the drastic reduction in income which had been imposed on the hospital since unification. One consequence was fewer trained nursing staff; East Germany was used to higher standards than West Germany. The old East 
German system, similar to the British, with health care free at the point of use for all, had been disbanded in favour of insurance.

\section{Community mental health services}

Day care in Germany often consists of a day hospital and day centre in the same premises. Usually funded by charitable organisations, the cost per patient is around DM180 (£72) per day. We visited one such centre called the Kieler Fenster (Window of Kiel). It provides an advice centre, employment consultancy service, sheltered occupational project and halfway residences. There are groups to support relatives and ex-patients. Programmes in the day hospital for patients with neurotic and psychotic disorders are separate.

Lübeck's day care is centred in a converted 17 th century granary called Die Brücke (Bridge). It has 150 places. Most patients have schizophrenia and attend datly. If patients fail to attend for two days they are visited at home by the centre's medical and social work staff. Only four of Lübeck's 27 private psychiatrists offer a domiciliary service.

Most rehabilitation in Germany is carried out in the community. The psychiatric hospital in Neustadt has an impressive residential rehabilitation project run by a psychologist teaching patients how to cope with schizophrenia. This includes education about the illness and prognosis, triggers for relapse, self-monitoring and coping strategies.

\section{Learning disabilities}

We saw a little of learning disability services. Vorwerk Hospital has about 500 patients looked after in a village-like setting. There are no plans to return patients to the community. As so many patients are looked after together various facilities are provided to occupy them, including a school, farm and workshop. There is even a miniature railway and riding stables.

Thirty years ago, all mental handicap patients requiring residential care in Schleswig-Holstein were in Neustadt Hospital. In 1966 the KarlSchuetze Heim was founded by a parents association in a pleasant rural location. It now houses 130 residents in a number of groups in separate units for varying levels of dependence.

\section{Alcohol services}

Alcoholism is a substantial problem in Germany. The German health department estimates there are $\mathbf{2 . 3}$ million problem drinkers. The annual per capita consumption of pure alcohol is 11.9 litres compared with 7 litres in Britain (The Brewers Society, 1992).

Frequency of admission is unrestricted and individuals have up to 80 in-patient detoxifications. If funded, residential rehabilitation can last from six weeks to four months, during which group therapy, work and occupational therapy, sport and fitness training all receive a strong emphasis.

The Fachklinik Freudenholm-Ruhleben in Kiel, seen by the tour, claimed a result of $40 \%$ abstinence at one year follow up with this regime. Thirty-five per cent had controlled drinking or minor relapse and $25 \%$ had complete relapse.

State-funded community care is poorly developed but independent self-help groups like Alcoholics Anonymous are numerous. In Lübeck there are $\mathbf{2 5}$ meetings of these each week.

\section{Drug addiction services}

We visited the 40 bed in-patient drug dependency unit at Ochsenzoll Hospital, Hamburg where it is estimated there are 10-13,000 opiate addicts out of a total population of 1.3 million. Twenty-six beds are used for a 12 day stabilisation programme. Fourteen beds are for a two to three week total withdrawal. Rehabilitation can be funded elsewhere for up to three months. All patients are informal but are asked to undress and be searched on admission. They are then asked to take a shower. The ward is locked and patients are only allowed to leave if escorted by staff, who are numerous. All patients are started on methadone $5 \mathrm{mg}$ b.d. with individuallytailored dose adjustment in the same volume thereafter. The patients are not told the dose or when their withdrawal will end. When sparingly given clonazepam or clonidine to suppress withdrawal symptoms they are not told the drug's name or dose.

One third of patients on the stabilisation programme are discharged having reached complete detoxification. On the longer programme two thirds reach this target and one third discharge themselves early. Long-term results have not been assessed but only one fifth of those detoxified have a further admission.

The staff feel that their service uses the most appropriate methods but there are not enough beds. Out-patient methadone prescription in Germany is extremely rare and requires stringent approval by the German Medical Council.

\section{Forensic psychiatry}

Each state in Germany has its own mental health legislation. Every compulsory admission has to be ratified by a court which can stipulate the 
length of treatment. Patients have a right of appeal.

The work of British regional secure units and special care hospitals is combined in a single department for each state. The unit for Schleswig-Holstein at Neustadt Hospital has 185 beds and a large multidisciplinary team.

Mechanical restraint is often used in Germany which may be because of less use of nursing observation.

\section{Comment}

In 1989 the per capita health expenditure in dollars in Germany was \$1232 compared with $\$ 836$ in Great Britain and \$2354 in the USA (Hospital Committee of the European Community, 1993). Despite good funding we did not see any evidence of over-staffing or wasteful spending of money. The level of nursing staff on acute wards appeared to match numbers in the UK. Charging fees for itemised types of treatment, however, could in our view be open to abuse by clinicians and drain resources.

German psychiatry clearly needs to undergo much development to improve the continuity of care between its acute services and psychiatrists working in their own practice. The latter also need to develop more of a multidisciplinary team approach. Only one psychiatrist in private practice in Hamburg did home visits and worked with a complete multidisciplinary team. We also feel that Germany needs to consider using ECT more appropriately.

The most impressive aspect of German psychiatry was the abundance of government funding in the former West Germany, resulting in some very good renovation of spacious old premises, far outshining any such work done in Britain. Its other great strength is the standard of equipment and furnishing in hostels and therapy departments. Patients were kept fully occupied throughout the day with an interesting variety of activities. Acute admissions wards were, however, very medical in style.

It will be interesting to see whether the differences between East and West amalgamate and whether German psychiatry develops community care away from a pattern which remains largely traditional.

\section{References}

Hosprtal Committee of THE EUROPEan COMmuntTy (1993) Hospital Services in the EC. ISBN 90-801546-1-X THE BREWERS SOCIETY (1992) Statistical Handbook.

S.D. Martin, Senior Registrar, Wonford House Hospital, Dryden Road, Exeter EX2 5AF; B. Bende, Senior Registrar, North Mersey Community NHS Trust, Rathbone, Mill Lane, Liverpool L13 4AW; B. Breitner, Registrar, Parkside Hospital, Victoria Road, Macclesfield SK10 3JS; M. Laker, Senior Registrar, Royal London Hospital Trust, Whitechapel Road, London E1 1BB; and F. Leslie, Consultant, Fair Mile Hospital, Wallingford, Oxon OX10 9HH

A large amount of literature was obtained on the tour. Correspondence and requests for further information to Dr Martin. 